\title{
SOBREVIVÊNCIA E MANUTENÇÃO DA ATIVIDADE NEMATOFÁGICA DO FUNGO Arthrobotrys musiformis SUBMETIDO À LIOFILIZAÇÃO
}

\author{
Survival and predatory activity of Arthrobotrys musiformis submitted to lyophilization
}

\author{
Adriana Mello Garcia ${ }^{1}$
}

\begin{abstract}
RESUMO
Devido ao grave problema de resistência desenvolvida por nematódeos aos antihelmínticos, importantes formas alternativas de controle têm sido pesquisadas, entre a quais, o controle biológico por meio de fungos nematófagos tem ganhado destaque. Para a utilização do controle biológico a campo, o grande desafio é produzir fungos nematófagos em massa e estocar por longos períodos sem perda das características de produção em massa e de sua atividade nematofágica. Os objetivos deste trabalho foram avaliar o processo de liofilização como meio de preservação e a sobrevivência de uma cepa autóctone de Arthrobotrys musiformis após incorporação em sal e sal mineral. Os resultados demonstraram que, através da metodologia empregada, o fungo quando armazenado sozinho, conservou sua viabilidade por pelo menos 60 dias. Entretanto, o fungo sobreviveu por apenas 1 dia após a incorporação no sal mineral e por 30 dias quando incorporado no sal.
\end{abstract}

Termos para indexação: Controle biológico, fungos nematofágicos, liofilização.

\section{ABSTRACT}

Due to the problem presented by parasites, when develop resistance to antihelmintic medical, important alternative procedures of parasites control has been researched, among then, the biological control by nematophagous fungi has great importance. In order to use biological control in field application, the challenger is to produce the nematophagous fungi massively and to storage it to long term without losing mass production and predatory capacity. The aim of this research work was to analyze the lyophilization as a method to preserve this specie of fungi and to incorporate in mineral salt and common salt. A strain of Arthrobotrys musiformis was employed. The results showed that the method allow the fungi to keep its viability, therefore, it could only survive for 1 day when incorporated do the mineral salt and 30 days in common salt.

Index terms: Biological control, nematophagous fungi, lyophilization.

(Recebido em 21 de dezembro de 2005 e aprovado em 17 de maio de 2006)

\section{INTRODUÇÃO}

O controle biológico tem sido apontado como um importante método alternativo e complementar de controle das helmintoses gastrintestinais de ruminantes, uma vez que problemas com resistência química têm sido cada vez maiores (MOTA et al., 2003a).

Desde a década de sessenta, vários agentes biológicos vêm sendo testados no controle biológico de nematódeos (PADILHA \& MENDOZA-DE-GIVES, 1996), sendo os fungos nematofágicos os que têm merecido maior destaque (MOTA et al., 2003a).

Dentre as espécies de fungos nematófagos, as produtoras de clamidósporos se distingüem pela resistência à passagem pelo trato gastrintestinal de animais, como é o caso do Duddingtonia flagrans e de algumas espécies de Arthrobotrys (CHANDRAWATHANI et al., 2004).

Entretanto, entre os principais entraves para o desenvolvimento de formulações comerciais estão a produção em massa, o armazenamento e a forma de administração para os animais (MOTA et al., 2003a).
Para o desenvolvimento dessas formulações, o estudo de métodos de preservação para aumentar a longevidade e estabilidade desses fungos é de vital importância. Assim, Nalepina et al. (1990) estocaram uma cepa de Arthrobotrys oligospora por meio de liofilização sob uma camada de óleo mineral, mantidos a $4^{\circ} \mathrm{C}$ em solo estéril, por cinco anos. Após esse período, o fungo foi testado quanto à preservação de sua capacidade predatória. Observaram que o fungo sobreviveu, mas que a capacidade de formação de armadilhas reduziu, demonstrando que estes eram métodos interessantes para manter coleções de fungos. Carneiro et al. (1996) também trabalharam com liofilização de Paecilomyces lilacinus e A. oligospora, e observaram que $P$. lilacinus sobreviveu por mais de 2 anos após a liofilização, mas que a manutenção em água destilada foi o melhor método de preservação de ambas as espécies de fungo.

Araújo et al. (2000) pesquisaram o efeito da temperatura e da incorporação ao sal de uma formulação de alginato de sódio contendo o fungo Arthrobotrys robusta e identificaram que temperaturas mais altas do 
que $35^{\circ} \mathrm{C}$ e o armazenamento em sal mineral diminuíam o crescimento do fungo.

Mota et al. (2003b) avaliaram o crescimento radial e produção de biomassa de A. robusta e Monacrosporium thaumasium submetidos a quatro diferentes métodos de preservação, sílica gel, mantidos a $4^{\circ} \mathrm{C}$ e manutenção em nitrogênio líquido a $-196{ }^{\circ} \mathrm{C}$ com e sem a adição de crioprotetores. Os autores identificaram que a manutenção em sílica gel e o congelamento sem crioprotetores interferiram negativamente no crescimento radial e produção de biomassa, demonstrando que a escolha do método de armazenamento desses microrganismos é fundamental para assegurar a capacidade predatória do fungo após períodos prolongados de manutenção.

Entretanto, não foram encontrados na literatura, trabalhos em que a liofilização do fungo A. musiformis tenha sido avaliada como método de preservação. Assim, este trabalho teve como objetivo verificar a sobrevivência de culturas do fungo nematófago autóctone $A$. musiformis, formador de clamidósporos, submetidas à desidratação por liofilização com a finalidade de facilitar o armazenamento e a sua incorporação em suplementos alimentares, tais como o sal comum, o sal mineral, e outras formulações comerciais.

\section{MATERIAL E MÉTODOS}

O fungo utilizado foi isolado em solo brasileiro, identificado e mantido na biblioteca da EMBRAPA-CNPGLMinas Gerais. Uma amostra, EMB 93, foi cedida e mantida em laboratório das dependências da Universidade Federal de Lavras, cultivada em meio de cultura sólido YPSSA (DALLAPRIA, 1992), em placas de petri com diâmetro de $10 \mathrm{~cm}$, por um período mínimo de trinta dias em estufas B.O.D. a $25^{\circ} \mathrm{C}$.

Após o cultivo, a superfície do ágar contendo as culturas foi raspada e colocada em tubos contendo $15 \mathrm{~mL}$ de água destilada estéril e uma gota de tween 80. Os tubos foram agitados em "vórtex" em três séries de 30 segundos para fragmentação mecânica do material cultivado. Após esse procedimento, o material foi congelado em nitrogênio líquido e submetido ao processo de liofilização.

O material liofilizado foi separado em três porções: uma alíquota com apenas o fungo liofilizado, uma porção de fungo liofilizado misturado em sal comum $(\mathrm{NaCl})$ e uma em sal mineral na proporção de 1:1. Cada alíquota de fungo puro e misturado foi mantida em duas temperaturas diferentes: a $4^{\circ} \mathrm{C}$ e em temperatura ambiente $\left(22^{\circ} \mathrm{C}\right.$ a $\left.26^{\circ} \mathrm{C}\right)$ em local fresco protegido do sol e de excesso de umidade. Em ambas as temperaturas o material fúngico foi mantido em câmaras de dessecação contendo sílica e armazenado por períodos de 1, 15, 30, 60 dias, período no qual foram avaliados quanto ao crescimento e atividade nematofágica in vitro.

O crescimento foi avaliado semeando-se alíquotas de cada amostra em placas de petri contendo meio de cultura YPSSA. Essas culturas foram observadas semanalmente para monitoramento do crescimento nas placas de petri. Nas placas positivas foi observado o crescimento de hifas e, posteriormente, feita a identificação de conídios característicos da espécie. Para a avaliação da atividade nematófaga o material foi também colocado em placas contendo agar água a $2 \%$ adicionados de nematóides de vida livre, Panagrellus redivivus. Para cada amostra foram feitas seis repetições. As leituras foram feitas com até 10 dias após a incubação em estufas B.O.D. a $25^{\circ}$ C. No processo de leitura, as placas só foram consideradas positivas quando havia o crescimento micelial, com produção de armadilhas e capturas de nematódeos.

\section{RESULTADOS E DISCUSSÃO}

Após a liofilização, o fungo se condensou não permanecendo fragmentado como antes do processo, contrariando a expectativa de se obter um material pulverizado como resulta a maioria dos processos de liofilização realizada com outros materiais. Essa característica reduziu as possibilidades de se utilizar este protocolo de produção e liofilização do fungo para sua utilização em formulações comerciais por não proporcionar uma boa homogeneização.

O material foi altamente higroscópico, pois, mesmo mantido em dessecadores, absorveu umidade rapidamente, o que pode ter contribuído para que o fungo emitisse os esporos e iniciasse um processo de crescimento vegetativo, o que reduz o seu período de sobrevivência.

O fungo puro se manteve viável após o processo de liofilização e durante todos os períodos de estocagem, tanto a $4^{\circ} \mathrm{C}$ quanto em temperatura ambiente, quando desafiado em placas, como apresentado na Tabela 1. Isso comprovou que o fungo sobreviveu tanto em baixas como em temperaturas ambientes por pelo menos 60 dias.

Como os resultados obtidos foram em percentuais de placas positivas (tabela 1), não se pode afirmar que a manutenção do fungo em temperatura ambiente tenha sido mais eficiente, embora tenha proporcionado um maior número de placas positivas, e não revelar tendência à redução do número de placas positivas em relação ao tempo de estocagem por até 60 dias.

Quando misturado ao sal comum e sal mineral, observou-se que os períodos de sobrevivência do fungo reduziram. No sal comum, o fungo cresceu e conseguiu predar larvas por até 30 dias de estocagem (tabela 2). 
TABELA 1 - Desafio in vitro de Arthrobotrhys musiformis puro mantido a $4^{\circ} \mathrm{C}$ e ambiente por $1,15,30$, e 60 dias.

\begin{tabular}{lcccc}
\hline \multirow{2}{*}{$\begin{array}{c}\text { Temperatura de } \\
\text { estocagem }\end{array}$} & \multicolumn{4}{c}{ Dias de estocagem (\% de placas positivas em seis repetições) } \\
\cline { 2 - 5 } & Dia 1 & Dia 15 & Dia 30 & Dia 60 \\
\hline $4^{\circ} \mathrm{C}$ & 83,3 & 66,7 & 33,3 & 33,3 \\
Ambiente & 100 & 66,7 & 100 & 50 \\
\hline
\end{tabular}

TABELA 2 - Desafio in vitro de Arthrobotrhys musiformis misturado ao sal comum, mantido a $4^{\circ} \mathrm{C}$ e temperatura ambiente por $1,15,30$, e 60 dias.

\begin{tabular}{lcccc}
\hline \multirow{2}{*}{$\begin{array}{c}\text { Temperatura de } \\
\text { estocagem }\end{array}$} & \multicolumn{4}{c}{ Dias de estocagem (\% de placas positivas em seis repetições) } \\
\cline { 2 - 5 } & Dia 1 & Dia 15 & Dia 30 & Dia 60 \\
\hline $4^{\circ} \mathrm{C}$ & 66,7 & 16,6 & 16,6 & 0 \\
Ambiente & 66,7 & 33,3 & 16,6 & 0 \\
$\left(22\right.$ a $\left.26^{\circ} \mathrm{C}\right)$ & & & \\
\hline
\end{tabular}

Nas placas semeadas com o fungo misturado em sal mineral a capacidade de predar larvas ocorreu apenas no período de 24 horas de estocagem.

A sobrevivência do fungo A. musiformis ao processo de liofilização concordaram com os de Carneiro et al. (1996) e Nalepina et al. (1990) que demonstraram a sobrevivência de outras espécies de fungos nematófagos à liofilização.

No presente trabalho, temperaturas baixas de $4^{\circ} \mathrm{C}$ não proporcionaram melhores taxas de sobrevivência. Outros autores que pesquisaram a viabilidade de fungos nematófagos submetidos a processos de armazenamento (ARAÚJO et al., 2000; MOTA et al., 2003b), e a diferentes temperaturas demonstraram que os fungos submetidos a baixas temperaturas sobrevivem melhor quando se faz a adição de crioprotetores. Como no processo de liofilização o material é submetido a temperaturas muito baixas pode-se supor que a adição de crioprotetores poderia melhorar a sobrevivência do fungo A. musiformis.

\section{CONCLUSÕES}

O processo de liofilização permite a sobrevivência do fungo A. musiformis por um período de até 60 dias, embora a qualidade do material não tenha permitido uma boa homogeneização. A mistura do fungo A. musiformis liofilizado com o sal comum e com o sal mineral reduz a sobrevivência e a capacidade de predação.

\section{REFERÊNCIAS BIBLIOGRÁFICAS}

ARAÚJO, J. V.; STEPHANO, M. A.; SAMPAIO, W. M. Effects of temperature, mineral salt and passage through the gastrointestinal tract of calves on sodium alginate formulation of Arthrobotrys robusta, a nematode trapping fungus. Revista Brasileira de Parasitologia Veterinária, Rio de Janeiro, v. 9, n. 1, p. 55-59, 2000.

CARNEIRO, S. M. T. P. G.; SILVA, J. F. V.; CARNEIRO, R. G. Evaluation of four methods on the survival of Paecilomyces lilacinus and Arthrobotrys oligospora. Nematologia Brasileira, Campinas, v. 20, n. 2, p. 63-67, 1996.

CHANDRAWATHANI, P.; JAMMAH, O.; ADNAN, M.; WALLER, P. J.; LARSEN, M.; GILLESPIE, A. T. Fields studies on the biological control of nematode parasites of sheep in the tropics, using the microfungus Duddingtonia flagrans. Veterinary Parasitology, Wageningen, v. 120, n. 3, p. 177-187, 2004.

DALLA-PRIA, M. Controle biológico de Meloidogyne incognita, raça 3 pelos fungos Verticillium chlamidosporium e espécies de Monacrosporium isolados ou combinados. 1992. $101 \mathrm{f}$. Dissertação (Mestrado) - Universidade Federal de Viçosa, Viçosa, 1992.

MOTA, M. A.; CAMPOS, A. K.; ARAÚJO, J. V. Controle biológico de helmintos parasitos de animais: estágio atual e perspectivas futuras. Pesquisa Veterinária Brasileira, Rio de Janeiro, v. 23, n. 3, p. 93-100, 2003a. 
MOTA, M. A.; CAMPOS, A. K.; ARAÚJO, J. V. Sporulation, radial growth and biomass production of Arthrobotrys robusta and Monacrosporium thaumasium submitted to different methods of preservation. Brazilian Journal of Microbiology, São Paulo, v. 34, p. 157-160, $2003 b$.

NALEPINA, L. N.; MATSKEVICH, N. V.; KOZHUKHAR, G. G.; TEPLYAKOVA, T. V. Effect of different methods on viability of nemathophagous predatory fungi. Mykologia I Fitopatologiya, [S.1.], v. 24, n. 1, p. 312-314, 1990.

PADILHA, T.; MENDOZA-DE-GIVES, P. Controle microbiano das formas de vida livre dos nematódeos tricostrongilídeos: uma alternativa para higienização das pastagens. In: PADILHA, T. Controle dos nematódeos gastrintestinais em ruminantes. Coronel Pacheco: Embrapa-CNPGL, 1996. p. 215-236. 